\title{
Branching Pattern of Brachial Artery with Accent to High up Division \& Clinical Significance
}

\author{
Khizer Hussain Afroze M', S.M. Badar Hayat ${ }^{2}$, Siraj Ahmed Shirbadgi ${ }^{3}$ \\ ${ }^{1}$ Assistant professor, Department of Anatomy, MVJ Medical College \& Research Hospital, Hoskote, Bangalore. Karnataka, India, ${ }^{2}$ Tutor, Department of \\ Anatomy, Narayan Medical College, Jamuhar, Bihar, India, ${ }^{3}$ Professor, Department of Anatomy, Basaveshwara medical college and Hospital, Chitradurga. \\ Karnataka, India.
}

\section{Abstract}

Introduction: The Brachial artery (BA) is used for various clinical procedures, particularly with respect to blood pressure monitoring and percutaneous arterial catheterization. A sound and accurate knowledge of anatomical variations regarding the BA especially higher division of BA are important for clinical diagnosis and surgical management of diseases of superior extremities. Because of such importance, we undertook the study to investigate the course and branching pattern of BA with special reference to high up division and to discuss its clinical significance. Subjects and Methods: A total of 50 formalin fixed upper limbs were utilized in the present study. The branching pattern of BA variability was studied. Results: Variation in the branching pattern of BA was observed in 8 specimens (16\%). The variations encountered were superior brachial artery (2\%), deep brachial artery (2\%), superficial ulnar artery (2\%), and superficial radial artery (10\%). Conclusion: The present study highlights the necessity for a thorough knowledge of brachial artery with respect to the high up division, to enhance the efficacy of diagnosis and for better surgical management of vascular diseases and injuries.

Keywords: Brachial artery, Bifurcation, High up division.

Corresponding Author: Dr. S.M. Badar Hayat, Tutor, Department of Anatomy, Narayan Medical College, Old GT Road, Rohtas District, Jamuhar, Bihar. India. 821305

Received: September 2019

Accepted: September 2019

\section{Introduction}

The Brachial artery is used for various clinical procedures, particularly with respect to blood pressure monitoring and percutaneous arterial catheterization, so the course and ramification of the vessels of the upper limbs have received attention for anatomists and surgeons. The origin and ramification of the brachial artery (BA) are important clinically because of its vascular role. It is the chief artery which supplies the whole upper limb. At the distal border of the tendon of teres major, the brachial artery (BA) arises as a continuation of the axillary artery. It usually terminates in the cubital fossa at the level of the neck of the radius into radial and ulnar arteries. ${ }^{[1]}$

Several studies in the review of literature have documented the variation in course and arterial pattern of upper limb especially higher incidence was observed in radial artery than ulnar artery. ${ }^{[2]}$ The most common anomaly of the arterial pattern is high up division of brachial artery where radial and ulnar arteries exhibit higher origin than usual i.e. proximal to the cubital fossa. The various nomenclatures have been used to describe the high up division of brachial artery, for example, superficial radial artery, superficial ulnar artery, brachioradial artery, superficial and deep brachial artery. The anomalous artery lies in a more superficial position and is named depending on the branching pattern and course it pursues in the arm and forearm. $^{[3]}$

A sound and accurate knowledge of anatomical variations regarding the higher division of brachial artery (BA) are important for clinical diagnosis and surgical management of diseases of superior extremities. An abnormal superficial course of arterial variation is often mistaken for superficial veins and accidental injection of certain drugs in these arteries may lead to a disastrous condition like gangrene or loss of hand. As their course is being superficial, there are more susceptible to trauma and bleeding. ${ }^{[4]}$

\section{Subjects and Methods}

The present study was carried on Department of Anatomy, in Sri Siddhartha Medical College, Tumakuru. A total of 50 formalin fixed upper limbs of different ages groups inclusive of both male \& female were utilized in the present study. The branching pattern of brachial artery variability was studied with careful examination and dissection.

In each specimen, the incision was made on the anterior or flexor compartment of arm, Cubital fossa and forearm and the dissection were carried out according to the Cunningham's manual of practical anatomy. The skin, superficial fascia, deep fascia was dissected and reflected. 
The brachial artery was traced from its origin. Any variation in the course \& branching pattern was recorded \& photographed.

\section{Results}

An observation concerning the different types of the branching pattern of the brachial artery especially higher division was shown in [Table 1]. In the present study, out of 50 specimens, we categorized our observation into four different types of the branching pattern of brachial artery based on its branches and level of termination. They are

1) Superficial brachial artery (SBA): arising from an axillary artery or proximal $1 / 3$ rd of the brachial artery, usually between the medial \& lateral roots of the median nerve. Bifurcation of the brachial artery usually occurs above the teres major muscles. Here artery crossing in front of the median nerve.

2) Deep brachial artery (DBA): always co-existing with SBA, bifurcation of the brachial artery occurs above the teres major muscles. Here artery crossing behind the median nerve.

3) Superficial Radial artery (SRA): defined as a radial artery with a high origin. The artery runs was initially medial to the median nerve, later it reaches the forearm by crossing superficial to the median nerve and runs its normal course in the forearm.

4) Superficial Ulnar artery (SUA): defined as an ulnar artery with a high origin. The artery runs was initially lateral to the median nerve, later it reaches the foramen by crossing superficial to the median nerve and runs its course superficial rather than deep in the forearm. It did not give out any branch before the cubital fossa

Table 1: Branching pattern of brachial artery based on the
level of termination
\begin{tabular}{|l|l|l|}
\hline Arterial pattern & Number & Percentage $(\%)$ \\
\hline Superficial Brachial Artery & 01 & $2 \%$ \\
\hline Deep Brachial Artery & 01 & $2 \%$ \\
\hline Superficial Radial Artery & 05 & $10 \%$ \\
\hline Superficial Ulnar Artery & 01 & $2 \%$ \\
\hline
\end{tabular}
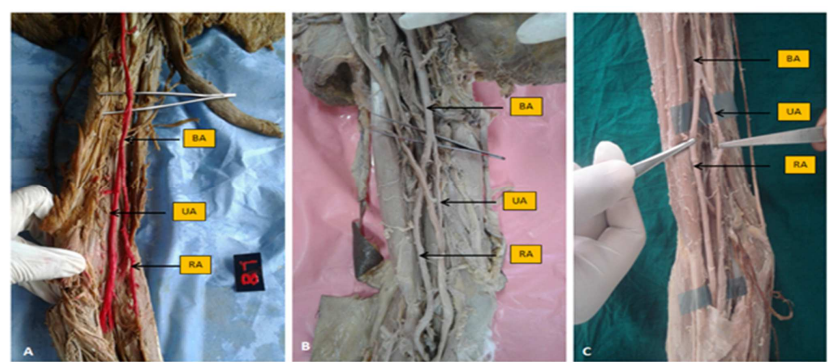

Figure 1: shows the higher division of the brachial artery at the middle of the arm. BA-Brachial artery, UA-Ulnar artery, RARadial artery.

Out of 50 formalin fixed upper limb specimens studied, 16\% (8 specimens) were found variation in the branching pattern of BA and $84 \%$ (42 specimens) showed the normal branching pattern of BA. In the present study, we observed the superficial radial artery (SRA) in 5 specimens (one left, two right and one bilateral; 10\%) out of 50 upper limbs of dissected cadavers. It was observed one of the $50(2 \%)$ upper limb specimens demonstrated the higher division of BA with the superficial ulnar artery (SUA). One specimen (2\%) showed a superficial and deep brachial artery.

In all the five specimens of SRA, immediately after the origin of the profunda brachii artery, the BA was divided into radial and ulnar arteries in the middle third of the arm. The radial artery in the arm was initially medial to the median nerve, later it reaches the foramen by crossing superficial to the median nerve and implicit its normal course in the forearm. Ulnar artery occupied the same position of the brachial artery in the arm and continuing as the ulnar artery in the forearm.

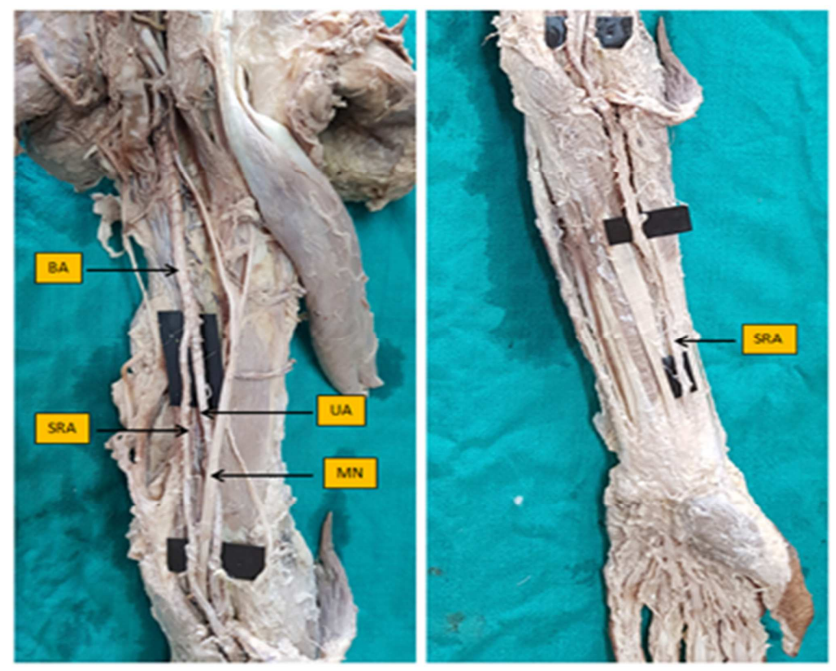

Figure 2: Shows the Superficial Radial artery with the high up division of the brachial artery. BA-Brachial artery, UA-Ulnar artery, SRA-Superficial Radial artery, MN- Median nerve.

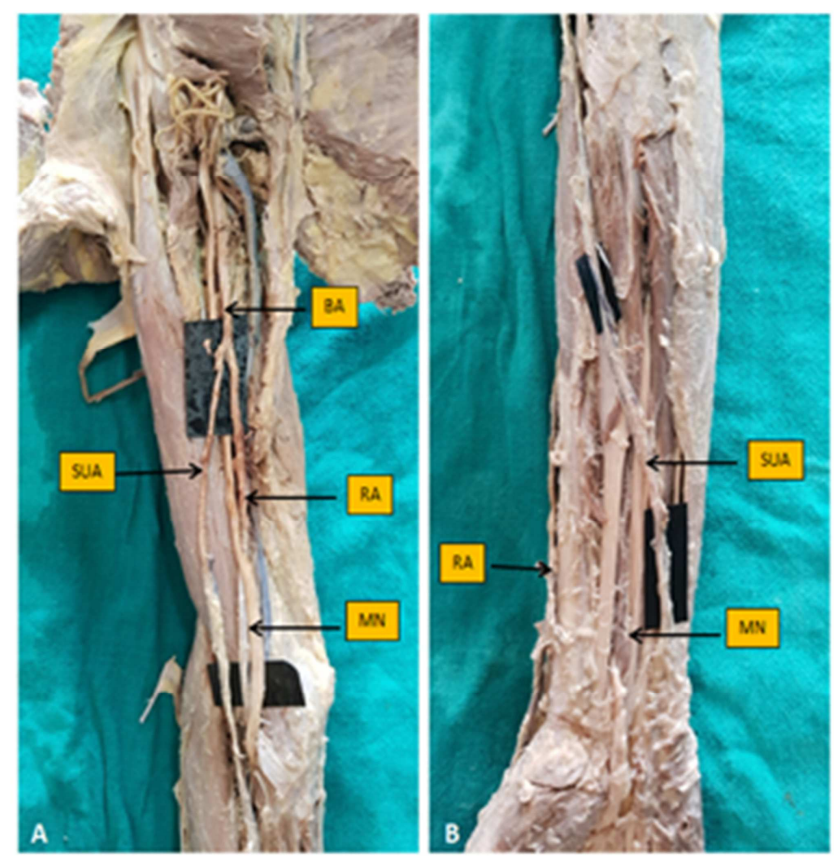

Figure 3: Shows the superficial ulnar artery with the high up division of the brachial artery. BA-Brachial artery, SUASuperficial Ulnar artery, RA- Radial artery, MN- Median nerve. 


\section{Afraze et al; Branching Pattern of Brachial Artery}

In one case (2\%), anomalous ulnar artery (Superficial Ulnar artery) originated from brachial artery little higher than normal and coursing superficial in the left upper limb of 59 years old male cadavers. The artery runs were initially lateral to the median nerve, later it reaches the foramen by crossing superficial to the median nerve and runs its course superficial rather than deep in the forearm. Radial artery engaged the same position of the brachial artery in the arm and continuing as a radial artery in the forearm after giving rise to the common interosseous artery.

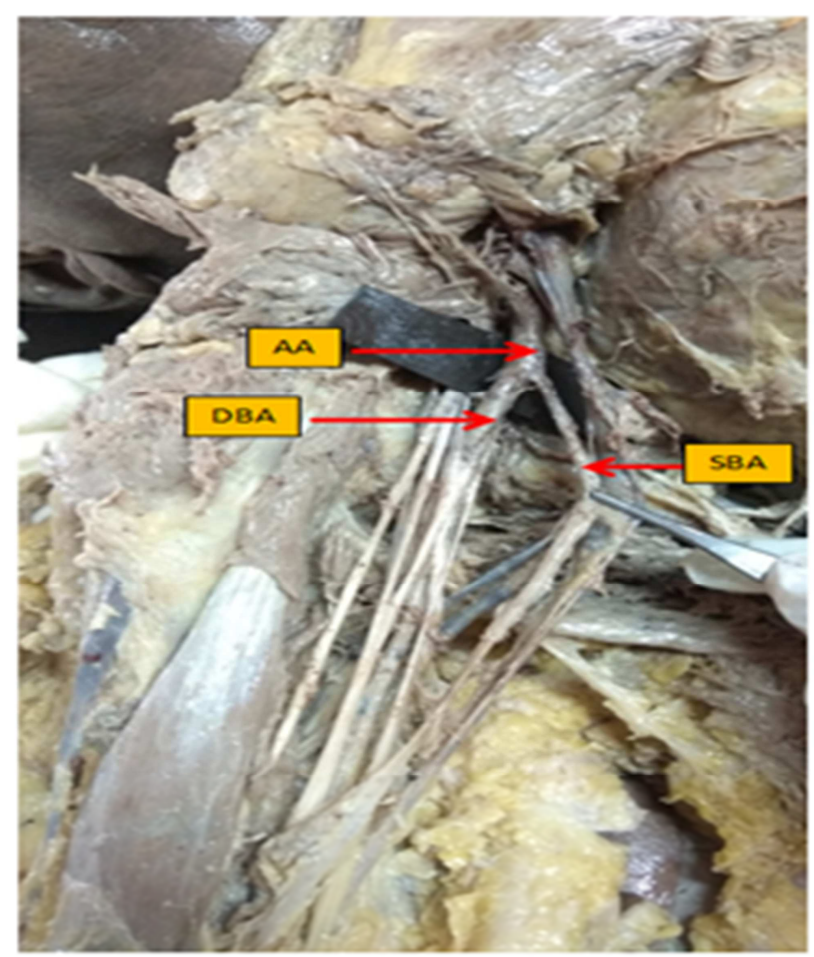

Figure 4: Shows the Superficial and Deep Brachial artery

Superficial brachial artery (SBA) and Deep brachial artery (DBA) was seen in the right upper limb of a 62-year-old male cadaver. SBA always co-existing with DBA, bifurcation of the brachial artery occurs above the teres major muscles. Brachial artery said to be superficial or deep based on its course over or behind the median nerve. SBA doesn't give any branches in the arm and terminated as radial and ulnar artery in the cubital fossa. Profunda brachial artery, superior and inferior ulnar collateral artery arises from DBA.

\section{Discussion}

Variations in the arterial pattern of the upper limbs have frequently been observed both in routine dissections and in clinical practice. Diversions from the typical anatomical arterial pattern of the upper limb are well documented. Arey and Jurjus postulated the six possible or potential theories which may lead to the anomalous blood vessels (i) the choice of unusual paths in the primitive vascular pattern (ii) the persistence of vessels of normally obliterated, (iii) vanishing of vessels normally retained, (iv) An incomplete development ( $\mathrm{v}$ ) the fusion or absorptions of the parts distinct (vi) A combination of factors leading to an atypical pattern normally encountered. ${ }^{[5,6]}$

In the present study, early bifurcation of BA in the middle of the arm giving rise to the superficial radial artery (SRA) was observed in 5 specimens (10\%). Celik H et al in 1996 conducted a similar study and observed the high division of BA is associated with SRA in two cadavers. In both the cases, just below the origin of profunda brachii artery, BA terminates into radial \& ulnar arteries. ${ }^{[7]}$ AI J et al in 2006 also documented a case of higher division of BA in the middle of the arm in association with SRA. They also added that the radial and ulnar artery was located in the medial and lateral side respectively. Profunda brachii artery was arising from the lateral aspect. ${ }^{[8]}$

Namani S et al in 2010 reported the similar case which shows the bizarre short segment brachial artery followed by high up division at the level of insertion of coracobrachialis into radial and ulnar artery. ${ }^{[9]}$ This type of high division was similar to the study done by author Vandana et al in 2012. The present study showed a slightly higher incidence when compared with the incidence of Vandana et al which accounts for $5 \%{ }^{[10]}$

In the present study, one specimen (2\%) showed superficial ulnar artery (SUA) which took origin from brachial artery little higher than normal and coursing superficial in the left upper limb. The artery runs were initially lateral to the median nerve, later it reaches the forearm by crossing superficial to the median nerve and runs its course superficial rather than deep in the forearm. In the literature review, we found that the various authors have reported the incidence of SUA which varies from $0.9-38 \% .^{[10]}$

Simic P et al in 2004 reported a case of SUA from brachial artery approximately $6 \mathrm{~cm}$ distal to profunda brachii artery. After crossing the median nerve ventrally, it ran superficial to flexor muscles of the forearm. SUA formed the superficial and deep palmar arches in association with branches of radial artery at the palm. ${ }^{[1]} \mathrm{A}$ similar finding of an unusual origin of SUA was reported by Jayasree et al (2017) of SUA in $2 \%$ of cases. ${ }^{[12]}$

Natsis in 2006 reported a case in which the superficial ulnar artery arises from the right axillary artery at the level of the junction of two roots of the median nerve and followed a looping course. In the upper and middle 1/3rd of the arm, SUA ran laterally to median nerve whereas in the lower $1 / 3$ rd of the arm the SUA crossed over the median nerve and ran medially to it in the cubital fossa, it passed superficial to the forearm flexor muscles. ${ }^{[13]}$ Keen et al in 1961, Rodriguez et al in 1995 and Vatsala et al in 2013 conducted a similar study and observed the incidence of brachioradial artery in association with SUA in $5.98 \%, 13.5 \%$, and $7.4 \%$ respectively. ${ }^{[14-16]}$ Such similar variation was not observed during the present study.

In the present study, we observed the incidence of the superficial brachial artery (SBA) and deep brachial artery (DBA) in one specimen (2\%). In this type of variation, bifurcation of the brachial artery occurs above the teres major muscles and more often, SBA always co-existing with DBA. Brachial artery said to be superficial or deep based on its course over or behind the median nerve. SBA doesn't give any branches in the arm and terminated as radial and ulnar artery in the cubital fossa. Profunda brachial artery, 


\section{Aproze et al; Branching Pattern of Brachial Artery}

superior and inferior ulnar collateral artery arises from DBA. Comparison of the incidence of SBA alone with different studies was tabulated in [Table 2]. But in the present study, we observed one specimen showed SBA along with DBA. Vatsala et al has conducted a similar study and reported the incidence of SBA along with DBA in 6 specimen which accounts for $11.1 \%$.

Table 2: Incidence of Superficial Brachial Artery (SBA) alone
by different authors.
\begin{tabular}{|l|l|l|l|}
\hline $\begin{array}{l}\text { SL. } \\
\text { NO }\end{array}$ & $\begin{array}{l}\text { NAME OF } \\
\text { AUTHORS }\end{array}$ & YEAR & PERCENTAGE \\
\hline 1. & Quains et al,${ }^{[17]}$ & 1844 & $0.2 \%$ \\
\hline 2. & Keen et al ${ }^{[13]}$ & 1961 & $12.3 \%$ \\
\hline 3. & Baeza et al,${ }^{[18]}$ & 1995 & $4.9 \%$ \\
\hline 4. & Patnaik VVG et al, ${ }^{[4]}$ & 2002 & $6.05 \%$ \\
\hline 5. & Vandana R et al, $^{[10]}$ & 2009 & $1.7 \%$ \\
\hline 6. & Vatsala et al, ${ }^{[16]}$ & 2013 & $1.9 \%$ \\
\hline
\end{tabular}

An abnormal superficial course of arterial variation is often mistaken for superficial veins and accidental injection of certain drugs in these arteries may lead to a disastrous condition like gangrene or loss of hand. As their course is being superficial, there are more susceptible to trauma and bleeding.

\section{Conclusion}

Variation in arterial pattern and its incidence could be especially important for clinicians and surgeons when performing invasive procedures in order to know the arteries they might expect when approaching a particular area. The arterial variation of the upper limb has been implicated in different clinical situations. As their course is being superficial especially superficial radial and ulnar artery, there are more susceptible to trauma and bleeding and also encountered during the elevation of forearm flap. Thus the knowledge of variability in the branching pattern of BA is helpful for clinicians for diagnostic evaluation, surgical management of vascular diseases and injuries.

\section{References}

1. Johnson D, Ellis H, Collins P, Standring S, editor. Gray's anatomy: the anatomical basis of clinical practice.39th ed. 90 Touttenham court road London W1T 4LP: Elsevier Churchill Livingstone; 2005. p 856

2. McCormack LJ, Cauldwell MD, Anson BJ. Brachial and antebrachial arterial pattern. Surg Gynae Obs. 1953; 96: 43-4.

3. Rosse C, Rosse PG. The free upper limb. Arm, forearm and hand. Hollinshed's text book of anatomy. 5th ed. Philadelphia. Lippincott-Raven. 1997. p.255-6.

4. Patnaik VVG, Kalse G, Singla RK. Branching pattern of brachial atery- a morphological study. J Anat Soc India. 2002;50(2):17680.

5. Arey LB. Developmental Anatomy.6th Ed. Philadelphia, W.B.Saunder's.1957; 375-7.

6. Jurjus A, Sfeir R, Bezirdjian R. Unusual variation of the arterial pattern of human Upperlimb. Anat Rec. 1986; 215:82-3.

7. Celik, H. H; Germus, G., Aldur, M.M.,and Ozcelik, M. Origin of the radial and ulnar arteries : variation in 81 arteriograms. Morphologie. 2001; 85:25-7.

8. AI J, Astaneh ME. A survey of variation in upper limb arteries. Journal of Iranian anatomical sciences.2006;4(2):193-6.

9. Namani Satyanarayana, P.Sunitha, Munvar Miya Shaik, P.Satyavathi Devi. Brachial artery with high up division with its embryological basis and clinical significance. International Journal of Anatomical Variation.2010; 3:56-8.

10. Vandana R, N M Suresh, Lakshmi Prabha R, Veena Pai. Variation in course and branching pattern of brachial artery. Anatomica Karnataka. 2012; 6 (3):42-8.

11. Simic P, Borovecki F, Jalsovec D, Jelic M, Martinovic S, Vinter I. The superficial ulnar artery originating from the left brachial artery. Italian journal of anatomy and embryology. 2004; 109(1):13-8.

12. Jayasree C, Kishan Reddy C. A Cadaveric study on variations in brachial artery - An Anatomical perspective. Perspectives in Medical Research. 2017; 5 (2): 29-32.

13. Natsis K, Papadopoulou AL, Paraskevas G, Totlis T, Tsikaras P. High origin of a superficial ulnar artery arising from the axillary artery: anatomy, embryology, cinical significance and a review of the literature. Folia morphologica. 2006;65(4):400-5.

14. Keen JA. A study of the arterial variations in the limb, with special reference to symmetry of vascular patterns. American Journal of Anatomy. 1961; 108: 245-261.

15. Rodriguez-Baeza A, Nebot J, Ferreira B, Reina F, Perez J, Sanudo JR, Roig M. An anatomical study and ontogenetic explanation of 23 cases with variations in the main pattern of the human brachioantebrachial arteries. Journal of Anatomy. 1995 Oct; 187(Pt 2):473.

16. Vatsala AR, Rajashekar HV, Angadi AV. Variation in branching pattern of brachial artery: a morphological and statistical study. Int J Biol Med Res. 2013; 4(1):2920-3.

Copyright: (C) the author(s), publisher. Academia Anatomica International is an Official Publication of "Society for Health Care \& Research Development". It is an open-access article distributed under the terms of the Creative Commons Attribution Non-Commercial License, which permits unrestricted non-commercial use, distribution, and reproduction in any medium, provided the original work is properly cited.

How to cite this article: Afroze MKH, Hayat SMB, Shirbadgi SA. Branching Pattern of Brachial Artery with Accent to High up Division \& Clinical Significance. Acad. Anat. Int. 2019;5(2):55-8.

DOI: dx.doi.org/10.21276/aanat.2019.5.2.15

Source of Support: Nil, Conflict of Interest: None declared. 